\title{
Influence of concentration and type of microcrystalline cellulose on the physical properties of tablets containing Cornelian cherry fruits
}

\author{
ALEŠ FRANC 1 \\ SLAVOMIR KURHAJEC ${ }^{1,2}$ \\ SYLVIE PAVLOKOVÁ ${ }^{1}$ \\ DANA SABADKOVÁ ${ }^{1, *}$ \\ JAN MUSELÍK ${ }^{1}$ \\ ${ }^{1}$ Department of Pharmaceutics \\ University of Veterinary and \\ Pharmaceutical Sciences \\ 61242 Brno, Czech Republic \\ ${ }^{2}$ Department of Pharmacognosy \\ and Botany, University of Veterinary \\ Medicine and Pharmacy, 04181 Košice \\ Slovakia \\ Accepted February 21, 2016 \\ Published online March 31, 2017
}

\begin{abstract}
The aim of this study was to find the optimal tablet composition with maximum content of dried fruits (Cornus mas L.). The effect of three different concentrations $(12.5,25$ and $50 \%$ ) of two types of microcrystalline cellulose (Avicel ${ }^{\circledR}$ PH 101 and Avicel ${ }^{\circledR}$ PH 200) and three different compression pressures $(20,60$ and $100 \mathrm{MPa})$ on the physical properties of tablet blends and tablets was studied. Tablets containing $50 \%$ Avicel $^{\circledR} \mathrm{PH} 101$ compressed under $100 \mathrm{MPa}$ were found to have the best physical properties. This combination of composition and compression pressure resulted in stable tablets even after storage under accelerated stability conditions (6 months, $40^{\circ} \mathrm{C}$ and $\left.75 \% \mathrm{RH}\right)$.

Keywords: Cornus mas, microcrystalline cellulose, direct compression, accelerated stability, principal component analysis
\end{abstract}

Lifestyle diseases such as cancer, cardiovascular diseases or diabetes mellitus type 2 are gradually becoming the global centre of attention as both direct and indirect economic costs increase each year. Therefore, new approaches to preventing the onset and progression of these diseases are being implemented. Antioxidants represent a promising supplement group with proven positive effects in the prevention of lifestyle diseases (1). Less commonly used plants and herbal remedies are becoming more and more popular sources of such antioxidants (2).

One of the most promising medicinal plants with a broad spectrum of antioxidants is Cornelian cherry (Cornus mas) whose medicinal effect has been known for years (3). Its antibacterial, astringent, antidiarrheal and hypolipidemic effect have been already studied (4-6). Moreover, the antidiabetic effect of Cornelian cherry, based on its antioxidant properties, has become a target of recent scientific studies (7). For these reasons, efforts have been made to process Cornelian cherry fruits into tablets without using extraction methods. A previously published work describes the main constituent substances and pharmacological effects of Cornelian cherry fruits and points to the

*Correspondence; e-mail: sabadkovad@vfu.cz 
relationship between the composition, process parameters and properties depending on the antioxidant activity of the final dosage form based on the Quality by Design approach (8).

The aim of the present experiment was to find the maximum possible amount of Cornelian cherry fruit that could be directly compressed into tablets. Relationships between the type and amount of filler and physico-mechanical properties of the resulting tableting blends and tablets were assessed by principal component analysis (PCA) and analysis of variance (ANOVA). Tabletting blends with two types of microcrystalline cellulose (MCC; Avicel ${ }^{\circledR}$ PH 101 and Avicel ${ }^{\circledR}$ PH 200) in three concentrations (12.5, 25 and $50 \%$ ) were prepared. The resulting tablets were evaluated twice, after the compression and after storage under accelerated stability conditions, to examine if the tablet quality deteriorated due the hygroscopicity of plant material (9). Assessment of tablet properties after stability testing was carried out using graphical comparison via interaction plots.

\section{EXPERIMENTAL}

\section{Material}

Cornelian cherry was hand-picked in Brno, Czech Republic, in September 2013. Microcrystalline cellulose (Avicel ${ }^{\circledR}$ PH 101 and Avicel ${ }^{\circledR}$ PH 200) and croscarmellose sodium (Ac-Di-Sol ${ }^{\circledR}$ ) were obtained from FMC Europe, Belgium. Colloidal silica (Aero$\mathrm{sil}^{\circledR}$ 200) was acquired from Evonik Industries, USA. Magnesium stearate was obtained from Peter Greven, Germany.

\section{Preparation of tableting blends}

Cornelian cherry fruits were manually pitted and dried on a filter paper at room temperature for three weeks. Final drying was performed in a hot air dryer (Horo, Type $38 \mathrm{~A}$, Germany) at $60{ }^{\circ} \mathrm{C}$ for 4 hours, which appears to be a gentle drying method for Cornelian cherry fruits (10). A mixture of $1.0 \mathrm{~kg}$ of Cornelian cherry fruits and $10.0 \mathrm{~g}$ of Aerosil ${ }^{\circledR} 200$ was inserted into the grinding vessel of a Stephan UMC 5 machine (Stephan Machinery GmbH, Germany). The vessel was hermetically sealed and left in a J 336-2 CLA freezer (Gorenje, Slovenia) at $-30{ }^{\circ} \mathrm{C}$ for $24 \mathrm{~h}$. After that, the vessel was removed from the freezer and the mixture was milled at $3000 \mathrm{rpm}$ for $5 \mathrm{~min}$. Addition of colloidal silica prevents the particles from sticking during the grinding. Moreover, colloidal silica has an antiplasticizing effect (enhancing the physical stability of powder), lowers hygroscopicity and improves physical properties of the mixture (beneficial for powder direct compression) (11). The vessel was opened after warming up to room temperature to lower the risk of atmospheric humidity precipitation on the powdered Cornelian cherry fruits. For each tablet batch, $200.0 \mathrm{~g}$ of tableting blend was prepared by mixing the individual ingredients (Table I) in a cubic blender AR 400 (Erweka $\mathrm{GmbH}$, Germany) at $30 \mathrm{rpm}$ for $10 \mathrm{~min}$. Magnesium stearate was then added into the mixture and mixing continued for another $5 \mathrm{~min}$. Overall, 6 batches of tableting blends were prepared. 
A. Franc et al.: E Influence of concentration and type of microcrystalline cellulose on the physical properties of tablets containing Cornelian cherry fruits, Acta Pharm. 67 (2017) 187-202.

Table I. Compositions of tableting blend

\begin{tabular}{lccccc}
\hline Batch name & $\begin{array}{c}\text { Milled } \\
\text { Cornelian } \\
\text { cherry }\end{array}$ & $\begin{array}{c}\text { Avicel } \\
\text { 101 }\end{array}$ & $\begin{array}{c}\text { Avicel }{ }^{\circledR} \text { PH } \\
200\end{array}$ & Ac-Di-Sol $^{\circledR}$ & $\begin{array}{c}\text { Magnesium } \\
\text { stearate }\end{array}$ \\
\hline MCC 101_12.5\% & 84.0 & 12.5 & - & 2.5 & 1.0 \\
MCC 101_25\% & 71.5 & 25.0 & - & 2.5 & 1.0 \\
MCC 101_50\% & 46.5 & 50.0 & - & 2.5 & 1.0 \\
MCC 200_12.5\% & 84.0 & - & 12.5 & 2.5 & 1.0 \\
MCC 200_25\% & 71.5 & - & 25.0 & 2.5 & 1.0 \\
MCC 200_50\% & 46.5 & - & 50.0 & 2.5 & 1.0 \\
\hline
\end{tabular}

Batch names in code: MCC - microcrystalline cellulose, 101 and 200 are types of Avicel ${ }^{\circledR} ; 12.5,25$ and $50 \%$ - MCC mass ratio. Colloidal silica (Aerosil ${ }^{\circledR} 200$ ) which was added before grinding is not mentioned in this table but is included in the amount of milled Cornelian cherry.

\section{Preparation of tablets}

Tableting blends were directly compressed at low, medium and high compression pressure (20, 60 and $100 \mathrm{MPa}$, respectively) using an eccentric tablet press EK-0 (Korsch GmbH, Germany). The compression rate was one tablet per $2 \mathrm{~s}$. A total of 18 batches of flat tablets, of $7 \mathrm{~mm}$ diameter and $150 \mathrm{mg}$ mass, were prepared.

\section{Stability studies}

Stability studies were performed as follows - 50 tablets were inserted into $60 \mathrm{~mL}$ low-density polyethylene bottles Bralen (Dr. Kulich Pharma, Czech Republic; $1 \mathrm{~mm}$ thickness; low vapour permeability) and the bottles were placed into a constant climate chamber $\mathrm{KBF} 115$ (Binder, Germany) at $40^{\circ} \mathrm{C}$ and $75 \% \mathrm{RH}$ for 6 months.

\section{Evaluation of tableting blends and tablets}

Generally, tablets undergo axial and radial relaxation after compression, which affects tablet properties such as mechanical strength or disintegration time. Accordingly, the tablets were stored under laboratory conditions in polyethylene zip bags for 72 hours after compression and were then evaluated. Tablet properties were evaluated repeatedly after storage under accelerated stability conditions.

\section{Density, Hausner ratio, compressibility index}

The tableting blend $(100.0 \mathrm{~mL})$ was weighted and tapped in a measuring cylinder using a tapped density tester SVM 102 (Erweka GmbH, Germany). After that, the values of bulk density $\left(D_{\mathrm{B}}\right)$, tapped density $\left(D_{\mathrm{T}}\right)$, Hausner ratio $(H R)$ and Carr compressibility index $(C I)$ were calculated according to Ph. Eur. (12). 


\section{Angle of repose and flow rate}

The tableting blend $(50.0 \mathrm{~g})$ was poured through the funnel of a flowability tester (Ing. Jaromír Havelka, Czech Republic) with an orifice diameter of $15 \mathrm{~mm}$. Time of flowing, height $(h)$, and radius $(r)$ of the poured powder were measured. Flow rate was expressed as the time that $100.0 \mathrm{~g}$ of sample needed to flow out of the funnel. Angle of repose was calculated using equation (1).

$$
\operatorname{tg} \alpha=h / r
$$

Results of both the angle of repose and flow rate are expressed as the mean value of three measurements (12).

\section{Particle size and size distribution}

Particle size and size distribution were evaluated by sieve analysis using a set of stainless steel sieves with apertures ranging from 80 to $3500 \mu \mathrm{m}$ (Retsch GmbH \& Co. KG, AS 200 basic, Germany). The tableting blend (100.0 g) was sieved at an amplitude of $50 \%$ for $10 \mathrm{~min}$ and the mass of fractions with different particle sizes was determined. Mean particle size was calculated using equation (2).

$$
\bar{d}=\frac{\sum_{\mathrm{i}=1}^{n} x_{\mathrm{i}} \times d_{\mathrm{i}}}{100}
$$

where $\bar{d}$ stands for mean particle size, $x_{\mathrm{i}}$ stands for average aperture size of upper and lower sieves of $i$ fraction, $d_{\mathrm{i}}$ stands for mass fraction percentage and $n$ stands for the number of sieves.

\section{Disintegration}

Six tablets from the same batch were inserted into a basket with six glass cylindrical tubes of a disintegration tablet tester Erweka ZT 4 (Erweka GmbH, Germany). The basket was moving vertically in a beaker filled with water at $37^{\circ} \mathrm{C}$. Tablet disintegration time was measured (12).

\section{Hardness and tensile strength of tablets}

A tablet was placed radially between the jaws of a tablet hardness tester C50 (Engineering Systems Ltd., UK) and the force needed to disrupt the tablet by crushing was determined. A total of 10 tablets were evaluated from each batch and the results are given as the mean values of these measurements. Tablet hardness was recorded as the breaking force $\left(B_{\mathrm{F}}\right)$ required to break the tablet. For better comparison, this value was also converted to tensile strength (TS) using the tablet height (He) and diameter (Di). (13). Tensile strength was calculated using the following formula (3):

$$
\mathrm{TS}=2 \mathrm{~B}_{\mathrm{F}} / \pi \mathrm{DiHe}
$$




\section{Freability of Tablets}

Twenty weighed tablets were placed in the drum of a friabilator Tar 10 (Erweka $\mathrm{GmbH}$, Germany), which was then rotated at $25 \mathrm{rpm}$ for 4 minutes. Any loose dust was removed from the tablets, which were then reweighed. Tablet friability was expressed as percentage mass loss (12).

\section{Height, diameter, mass and density of tablets}

Twenty tablets were places into the sample carousel of an automated tablet testing system Pharmatest WHT-2 (Pharmatest, Germany). Mass, thickness and diameter of the tablets were determined. Mean values for each tablet batch were calculated.

Tablet density was calculated from the mean values of tablet height $(\mathrm{He})$, diameter (Di) and Mass (We) using equation (4):

$$
\rho=\frac{\pi \cdot\left(\frac{D i}{2}\right)^{2} \cdot H e}{W e}
$$

\section{Data analysis}

First, exploratory data analysis and essential descriptive statistics were carried out. Data pretreatment for multivariate analysis included logarithmic transformation to achieve a normal distribution, followed by column centring and scaling to unit variance and zero mean. The PCA model was then calculated to explain the dependence structure between the composition of tablets and their physico-mechanical properties, namely, friability, density and disintegration time. Statistical significance of the MCC concentration and the type of MCC and their interaction were tested using ANOVA with visualization via interaction plots, which also displayed the influence of stability testing on the selected properties. Data analysis was performed by means of software R, version 3.2.2 (14).

\section{RESULTS AND DISCUSSION}

In order to prepare powdered tableting blends and thereafter tablets, it was necessary to modify Cornelian cherry fruits. Since dried fruits were too plastic for milling under laboratory conditions, their brittleness had to be increased. It was found that addition of colloidal silica and freezing of plant material facilitated the grinding process (15). Particle size distribution of ground fruits is shown in Fig. 1.

\section{Evaluation of tableting blends}

Six different blends with various physical properties were obtained by mixing ground Cornelian cherry fruits and colloidal silica with two types of microcrystalline cellulose in three concentrations. Different compression force was also established in the case of tablets. Results of the physical properties evaluation are summarized in Table II. Data for tableting blends were not compared using statistical significance testing. 


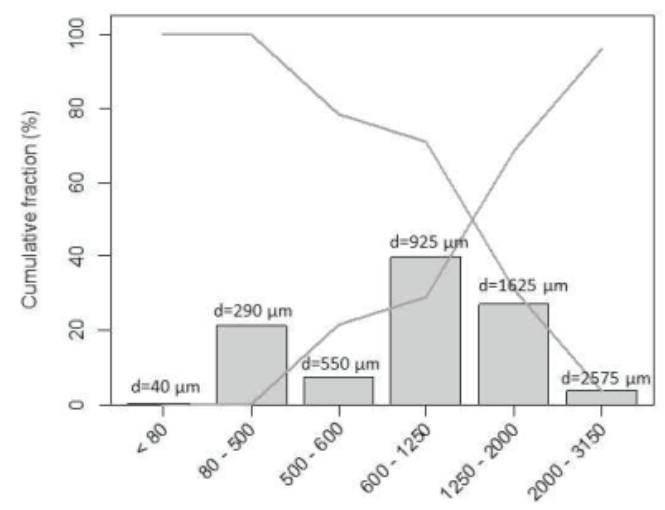

Fig. 1. Particle size distribution ( $d=$ mean particle size of each fraction).

It is obvious that the flow rate lowered with the amount of MCC while, in all three concentrations, the tableting blends containing Avice ${ }^{\circledR} \mathrm{PH} 101$ achieved lower flow rate than blends containing Avicel ${ }^{\circledR}$ PH 200. This indicates that Avicel ${ }^{\circledR}$ PH 200 has bigger and more spherical particles and thus the flow rate increases (16). Angle of repose increased with the increasing amounts of Avicel ${ }^{\circledR} \mathrm{PH}$ 101. In contrast, increasing amounts of Avicel ${ }^{\circledR}$ PH 200 resulted in a decreased angle of repose. This difference can be explained by the fact that individuals fillers manifest their properties in difference way in blends with other substances (17). However, it can be seen that blends containing Avicel $^{\circledR}$ PH 200 achieved a lower angle of repose than the corresponding blends with Avicel ${ }^{\circledR} \mathrm{PH}$ 101. This finding corresponds to the properties of binders themselves (17).

According to Ph. Eur, the angle of repose was excellent in all blends (12). When assessing flow properties using the compressibility index $(C I)$ and Hausner ratio $(H R)$, the properties worsened with increasing amounts of MCC. Blends with Avicel ${ }^{\circledR}$ PH 200 reached slightly better flow properties, which concurs with the published literature (18). All the $C I$ and $H R$ values ranged between excellent and good (12).

Table II. Evaluation of tableting blends

\begin{tabular}{lcccccc}
\hline Batch name & $\begin{array}{c}A R \\
\left({ }^{\circ}\right) \\
\text { value } R S D\end{array}$ & $\begin{array}{c}F R \\
\left(\mathrm{~g} \mathrm{~s}^{-1}\right) \\
\text { value } R S D\end{array}$ & $\begin{array}{c}D_{\mathrm{B}} \\
\left(\mathrm{g} \mathrm{cm}^{-3}\right) \\
\text { value }\end{array}$ & $\begin{array}{c}D_{\mathrm{T}} \\
\left(\mathrm{g} \mathrm{cm}^{-3}\right) \\
\text { value }\end{array}$ & $\begin{array}{c}H R \\
\text { value }\end{array}$ & $\begin{array}{c}C I \\
\text { value }\end{array}$ \\
\hline MCC 101_12.5\% & 21.819 .53 & 20.622 .33 & 0.73 & 0.78 & 1.08 & 7.14 \\
MCC 101_25\% & 21.6114 .58 & 14.186 .14 & 0.62 & 0.74 & 1.18 & 15.28 \\
MCC 101_50\% & 24.548 .03 & 13.917 .62 & 0.60 & 0.70 & 1.17 & 14.63 \\
MCC 200_12.5\% & 20.715 .36 & 25.970 .50 & 0.68 & 0.73 & 1.06 & 5.63 \\
MCC 200_25\% & 20.253 .06 & 24.881 .81 & 0.68 & 0.73 & 1.07 & 6.76 \\
MCC 200_50\% & 19.498 .05 & 16.642 .40 & 0.60 & 0.68 & 1.12 & 10.84 \\
\hline
\end{tabular}

$A R$ - angle of repose, $F R$ - flow rate, $D_{\mathrm{B}}$ - bulk density, $D_{\mathrm{T}}$ - tapped density, $H R$ - Hausner ratio, $C I$ - Carr compressibility index, $R S D$ - relative standard deviation. 
A. Franc et al.: E Influence of concentration and type of microcrystalline cellulose on the physical properties of tablets containing Cornelian cherry fruits, Acta Pharm. 67 (2017) 187-202.

These decreased with increasing amounts of MCC. Therefore, MCC has lower density than powdered Cornelian cherry fruits. Different results for flow characteristics are caused by the different physical principles of individual evaluation methods. While the angle of repose and flow through the orifice are mainly influenced by particle size and shape, $C I$ and $H R$ are based on different densities/thickening abilities of blends. Differentness of these methods and their mutual comparison are extensively described in literature (19).

Blends containing Avicel ${ }^{\circledR} \mathrm{PH} 101$ have slightly higher tapped density compared to those with Avicel ${ }^{\circledR} \mathrm{PH} 200$. It has been documented that smaller particles of Avicel ${ }^{\circledR} \mathrm{PH}$ 101 get into interparticular spaces and the resulting densities are then higher than in the case of Avicel ${ }^{\circledR} \mathrm{PH} 200$. This also explains higher $C I$ and $H R$ values in samples with Avicel ${ }^{\circledR}$ PH 101 (20). As regards bulk density values, this tendency is not entirely followed since blends containing $50 \% \mathrm{MCC}$ have the same $D_{\mathrm{B}}$. Moreover, samples comprising $25 \%$ Avicel $^{\circledR} \mathrm{PH} 200$ have even higher $D_{\mathrm{B}}$ than the corresponding blend with Avicel ${ }^{\circledR}$ PH 101. This discrepancy between $D_{\mathrm{B}}$ and $D_{\mathrm{T}}$ values can be explained by the uneven distribution of extraparticular air that is removed during tapping.

However, the actual impact of all aspects of flow properties on tablet quality can be assessed only by evaluation of tablet properties, mainly mass uniformity of the resulting tablets.

\section{Evaluation of tablets}

Since mass uniformity is not affected by the compression pressure, samples 1,2 and 3 were assessed as triple evaluation of mass uniformity in all blends (Table III). Relative standard deviation (RSD) determined from these three measurements was used in PCA. When evaluating mass uniformity by the pharmacopoeial criteria for tablets weighing $150 \mathrm{mg}$, most of the samples did not pass the evaluation since the maximum mass variation for tablets up to $250 \mathrm{mg}$ is $\pm 7.5 \%$ (12).

The only exception is the sample with $50 \%$ Avicel ${ }^{\mathbb{B}} \mathrm{PH} 101$, which passed the limit closely. Nevertheless, this blend reached the slowest flow rate and the highest angle of repose (Table II), indicating difficult interpretation of the blend flow properties and tablet mass uniformity correlation (21).

For visualization of dependencies on the composition of tablet blends, their properties and tablet mass uniformity (represented by relative standard deviation) the PCA model was built. The first two principal components (PCs) explain $78.0 \%$ of variability, which is a sufficient amount to provide a reliable description of the data structure (22). The PCA biplot (Fig. 2a) displays a projection of samples and variables in the new space of the first two PCs. Samples far apart differ from each other, while samples closely spaced have similar properties. Original variables are depicted as arrows, whose lengths are directly proportional to the explained variability; the angle between any two arrows indicates the measure of correlation. The graph clearly shows the differences between samples of tablet blends due to the distance of points; no clustering of objects according to the type or concentration of MCC is observed. Distribution of samples along the first principle component $(\mathrm{PC} 1)$ is predominantly related to the varying concentration of $\mathrm{MCC}$ - concentration decreases from left to right in the graph. The second principal component (PC2) is associated with the MCC type - points corresponding to MCC 101 can be seen towards the top 


\begin{tabular}{|c|c|c|c|c|c|c|c|c|c|c|c|c|c|c|}
\hline \multirow[t]{2}{*}{ Batch name } & \multicolumn{3}{|c|}{ 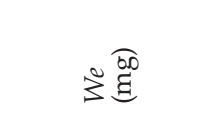 } & \multicolumn{2}{|c|}{$\widetilde{\Xi}$ ह્વ } & \multicolumn{2}{|c|}{ 急 } & 庄 & \multicolumn{2}{|c|}{ 泣 } & $\omega \stackrel{\overparen{E}}{\tilde{E}}$ & 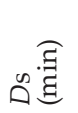 & \multicolumn{2}{|c|}{ 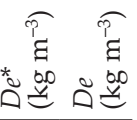 } \\
\hline & 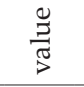 & 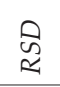 & $\mathrm{N}^{\stackrel{\times}{\rightleftarrows}}$ & 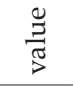 & $\begin{array}{l}\hat{2} \\
\approx\end{array}$ & $\underset{\frac{0}{3}}{\frac{0}{7}}$ & $\begin{array}{l}\text { कि } \\
\text { ₹ }\end{array}$ & $\stackrel{\frac{0}{2}}{\frac{\pi}{>}}$ & $\frac{\mathbb{g}}{\frac{\pi}{3}}$ & $\begin{array}{l}\text { कि } \\
\text { \& }\end{array}$ & 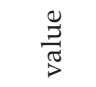 & $\frac{\mathscr{g}}{\frac{2}{2}}$ & $\frac{\cong}{ٍ ్}$ & $\frac{0}{2}$ \\
\hline \multicolumn{15}{|c|}{ After compression } \\
\hline MCC 101_12.5\%_1 & 153.4 & 3.0 & 5.5 & 6.60 & 1.1 & 3.74 & 2.6 & 0.63 & $\mathrm{~N}$ & $A$ & NA & 16 & 1199 & 1066 \\
\hline MCC 101_12.5\%_2 & 147.1 & 3.3 & 8.1 & 6.63 & 0.9 & 3.53 & 3.9 & 0.53 & $\mathrm{~N}$ & A & NA & 18 & 1208 & 1083 \\
\hline MCC 101_12.5\%_3 & 148.1 & 2.2 & 4.1 & 6.61 & 1.1 & 3.57 & 2.0 & 0.89 & $\mathrm{~N}$ & A & NA & 18 & 1210 & 1079 \\
\hline MCC 101_25\%_1 & 157.7 & 2.9 & 5.5 & 6.91 & 0.5 & 3.56 & 3.8 & 0.30 & $\mathrm{~N}$ & A & NA & 3 & 1182 & 1152 \\
\hline MCC 101_25\%_2 & 149.8 & 6.7 & 12.2 & 6.90 & 0.6 & 3.40 & 7.0 & 0.54 & $\mathrm{~N}$ & A & NA & 4 & 1179 & 1145 \\
\hline MCC 101_25\%_3 & 152.3 & 2.1 & 3.7 & 6.90 & 0.7 & 3.49 & 3.9 & 0.35 & $\mathrm{~N}$ & A & NA & 10 & 1168 & 1135 \\
\hline MCC 101_50\%_1 & 151.5 & 3.1 & 7.4 & 7.00 & 0.1 & 3.12 & 2.6 & 0.17 & 29.6 & 12.4 & 863.26 & 1 & 1262 & 1262 \\
\hline MCC 101_50\%_2 & 150.9 & 1.6 & 2.1 & 7.00 & 0.1 & 3.10 & 4.0 & 0.14 & 29.6 & 10.5 & 868.83 & 2 & 1265 & 1265 \\
\hline MCC 101_50\%_3 & 150.4 & 4.1 & 7.1 & 7.01 & 0.2 & 3.07 & 4.4 & 0.18 & 33.3 & 7.9 & 985.57 & 3 & 1270 & 1274 \\
\hline MCC 200_12.5\%_1 & 148.8 & 4.2 & 8.9 & 6.80 & 0.27 & 3.52 & 3.8 & 0.17 & \multicolumn{2}{|c|}{ NA } & NA & 15 & 1165 & 1099 \\
\hline MCC 200_12.5\%_2 & 159.0 & 2.9 & 6.3 & 6.57 & 1.0 & 3.85 & 3.5 & 0.30 & \multicolumn{2}{|c|}{ NA } & NA & 16 & 1219 & 1074 \\
\hline MCC 200_12.5\%_3 & 156.1 & 3.0 & 6.3 & 6.66 & 0.7 & 3.80 & 2.8 & 0.37 & \multicolumn{2}{|c|}{ NA } & NA & 20 & 1180 & 1068 \\
\hline MCC 200_25\%_1 & 146.9 & 1.8 & 4.2 & 6.85 & 1.2 & 3.45 & 2.5 & 0.58 & \multicolumn{2}{|c|}{ NA } & NA & 8 & 1156 & 1107 \\
\hline MCC 200_25\%_2 & 158.8 & 6.9 & 13.8 & 6.83 & 1.0 & 3.75 & 8.7 & 0.75 & \multicolumn{2}{|c|}{ NA } & NA & 11 & 1156 & 1101 \\
\hline MCC 200_25\%_3 & 150.9 & 2.3 & 4.0 & 6.84 & 0.8 & 3.60 & 3.0 & 1.11 & \multicolumn{2}{|c|}{ NA } & NA & 11 & 1141 & 1090 \\
\hline MCC 200_50\%_1 & 153.3 & 3.9 & 8.0 & 6.99 & 0.2 & 3.84 & 4.0 & 2.07 & 7.2 & 20.5 & 170.85 & 1 & 1041 & 1038 \\
\hline MCC 200_50\%_2 & 158.4 & 2.3 & 4.2 & 6.99 & 0.1 & 3.52 & 2.9 & 0.90 & 12.6 & 15.5 & 326.18 & 1 & 1173 & 1170 \\
\hline MCC 200_50\%_3 & 154.3 & 3.1 & 5.6 & 6.99 & 0.2 & 3.39 & 4.7 & 2.49 & 14.4 & 18.1 & 387.07 & 1 & 1187 & 1183 \\
\hline
\end{tabular}

Batch names: MCC - microcrystalline cellulose; 101 and 200 are types of Avicel ${ }^{\circledR} ; 12.5,25$ and $50 \%$ - MCC mass ratio, $1=20 \mathrm{MPa} ; 2=60 \mathrm{MPa} ; 3=100 \mathrm{MPa}$; We - mass, $T_{\max }$ - maximal deviated value (\%), Di - diameter, $\mathrm{He}$ - height, $\mathrm{Fr}$ - friability, $\mathrm{Ha}$ - hardness, Ts - tensile strength, $\mathrm{Ds}$ - disintegration, $\mathrm{De}$ - density ( ${ }^{*}$ for measured $\mathrm{Di}$ values), NA - not applicable.

of the graph, while samples with MCC 200 are at the bottom. This depiction also indicates negligible extent of correlation between mass uniformity (RSD) and other variables. The value of RSD is very closely correlated with axis PC2, so PC2 is considerably influenced by RSD, in contrast to PC1, which is not affected by RSD. This means that mass uniformity primarily depends on the type of MCC.

Tablet friability lowered with increasing contents of Avicel ${ }^{\circledR} \mathrm{PH} 101$. In contrast, increasing amounts of Avicel ${ }^{\circledR}$ PH 200 increased the friability. The lowest friability was reached in the sample containing $50 \%$ Avicel $^{\circledR} \mathrm{PH}$ 101, proving high tablet mechanical strength and better compression characteristics of Avicel ${ }^{\circledR}$ PH 101 (16). 
A. Franc et al.: E Influence of concentration and type of microcrystalline cellulose on the physical properties of tablets containing Cornelian cherry fruits, Acta Pharm. 67 (2017) 187-202.

Disintegration time was shortened with increasing contents of both Avicel ${ }^{\circledR}$ types. In general, shorter disintegration times were reached in samples containing Avicel ${ }^{\circledR} \mathrm{PH}$ 101. Samples containing $12.5 \% \mathrm{MCC}$ did not pass the pharmacopoeial criterion for acceptable disintegration time, which is up to 15 minutes (12).

The tablet hardness/tensile strength in samples containing 12.5 or $25 \% \mathrm{MCC}$ was unmeasurable since the tablets were too plastic and were squashed and crumbled during the evaluation. Therefore, the tablet hardness tester could not evaluate the break point of tablets. The highest hardness/tensile strength was reached in samples containing $50 \%$ Avicel ${ }^{\circledR} \mathrm{PH} 101$ and the hardness/tensile strength did not increase with the compression pressure. Since the different compression pressures do not extensively affect tablet dimensions, the hardness and tensile strength values basically correlate.

During the assessment of tablet diameter, the tablet is slightly clasped by the device jaws before the measurement is recorded. This can distort the diameter values in plastic tablets since the pressure deforms tablet structure and the measured diameter is therefore smaller than the real one given by the matrix of the tableting press punch. This is evident in tablets containing more plant material (12.5 and $25 \% \mathrm{MCC}$ ). Hence, tablet density was calculated twice - using the measured diameter $\left(D e^{*}\right)$ and using the compression matrix diameter $(D e)$.

As tablet diameter was considerably different from the compression matrix diameter, tablet densities were calculated twice - using the measured diameter $\left(D e^{*}\right)$ and using the compression matrix diameter $(D e)$. Tablet density increased with the compression pressure and higher densities were achieved in blends containing Avicel ${ }^{\circledR}$ PH 101. The densest sample and therefore the most compressed one was the composition containing Avicel ${ }^{\circledR} \mathrm{PH} 101$.

The resulting PCA model for the evaluation of tablets contains variables: disintegration time, friability and density. The first two principal components describe together $95.4 \%$ of total variability. Biplot for the PCA model (Fig. 2b) clearly displays grouping of objects in the ordination space according to the combination of MCC type and concentration. $\mathrm{PC} 1$ is explained mainly by variable $D e, \mathrm{PC} 2$ is predominantly correlated with variables $D s$ (positive correlation) and $F R$ (negative correlation). Differentiation of samples according to MCC type is primarily related to $\mathrm{Fr}$, segmentation based on MCC concentration can be observed according to the $D s$ value (inverse relationship). Samples with different MCC 101 concentrations can be distinguished due to the values of De. Similar characteristics of samples processed by different compression pressures are observed, except for samples MCC $200-50 \%$, where the corresponding points in the graph are relatively far apart. In contrast to tableting blends, conclusions on the dependencies in tablet characteristics are confirmed also by ANOVA as a result of the larger data set. ANOVA presents $p$-values as a decisive criterion for indication of a parameter as significant. Statistical testing was evaluated for the level of significance of $a=0.05$, so $p$-values equal to or smaller than $a$ mean that the parameter is statistically significant. Significance of MCC concentration, MCC type and their mutual interaction were assessed.

Disintegration time is mainly influenced by the percentage content of MCC ( $p<$ $0.001)$, regardless of the MCC type $(p=0.516)$. Statistical insignificance of the interaction between the content and type of MCC was also observed $(p=0.642)$. 
a)

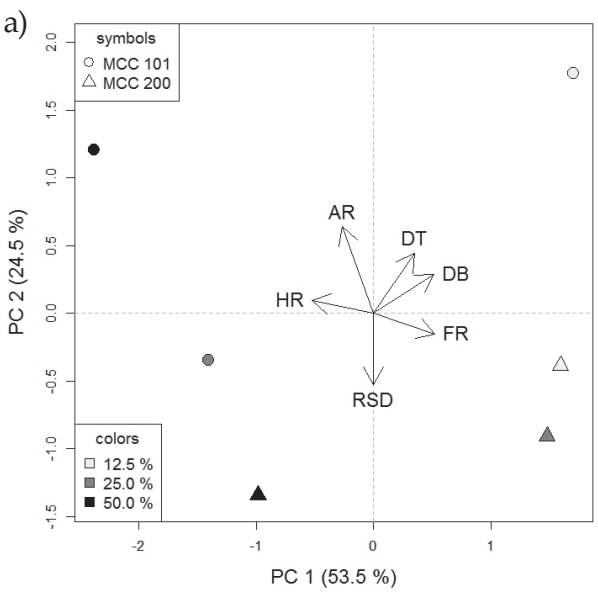

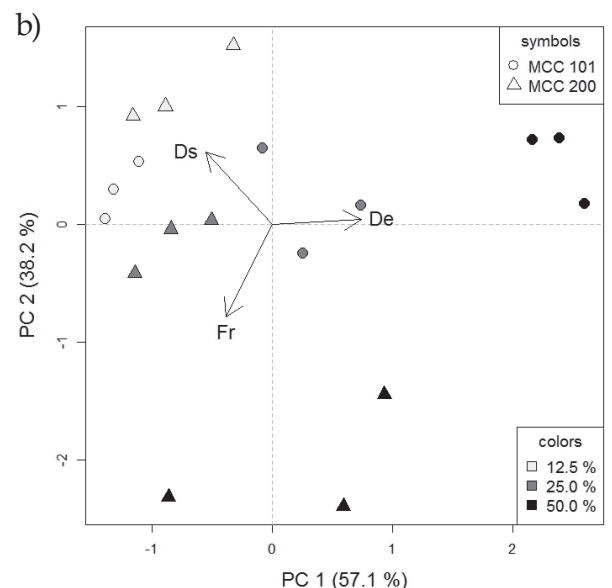

Fig. 2. PCA biplot for: a) tableting blends and tablets and b) tablets only. Objects in models: samples MCC 101 and MCC 200 (differentiated by symbols); percentage content of MCC: $12.5 \%, 25 \%, 50 \%$ (differentiated by gray); variables included in models: angle of repose $(A R)$, tapped density $\left(D_{T}\right)$, bulk density $\left(D_{B}\right)$, flowrate $(F R)$, Hausner ratio $(H R)$, mass uniformity $(R S D)$, disintegration time $(D s)$, density $(D e)$ and friability $(F r)$.

Regarding the density and friability evaluation, all $p$-values were considerably smaller than 0.05, so statistical significance of MCC percentage content, MCC type and their interaction were confirmed. The value of density depended heavily on the Avicel ${ }^{\circledR}$ PH 101 content, while it remained almost unchanged for Avicel ${ }^{\circledR}$ PH 200. In contrast to

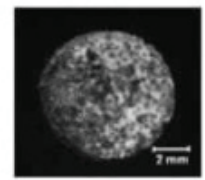

MCC 101_125\%_1

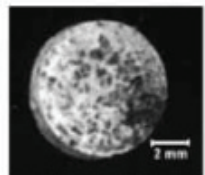

MCC 101_25\%_1

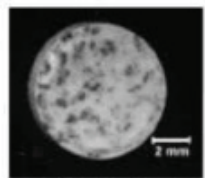

MCC $10150 \%$ _

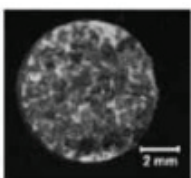

MCC 101_12.5\%_2
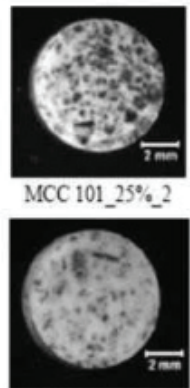

MCC 101_50\%_2

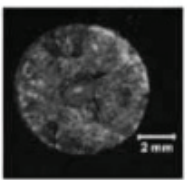

MCC 101_125\%_3
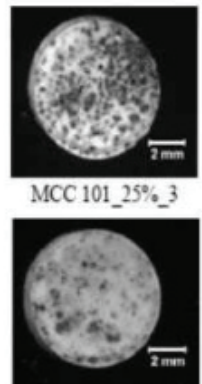

MCC 101_50\%_3

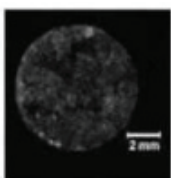

MOC 200_12.5\%_1

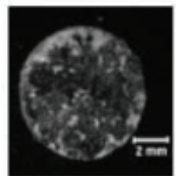

MCC 200_25\%_1

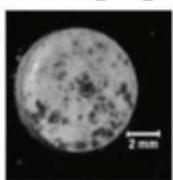

MCC $20050 \%$ _ 1

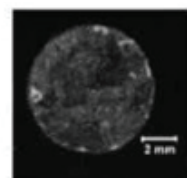

MCC 200_12.5\%_2

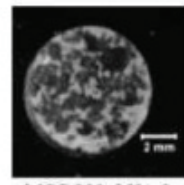

MCC 200_25\%_2

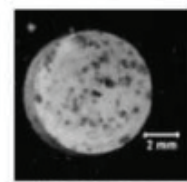

MCC 200 50\% 2 2
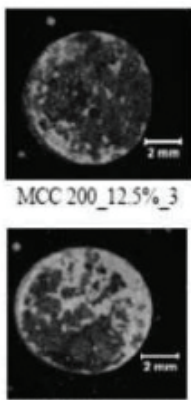

MCC 200_25\%_3

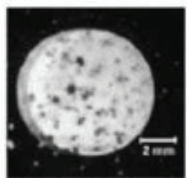

MCC 200_50\% 3

Fig. 3. Top view of tablets (diameter $7 \mathrm{~mm}$ ). 
A. Franc et al.: E Influence of concentration and type of microcrystalline cellulose on the physical properties of tablets containing Cornelian cherry fruits, Acta Pharm. 67 (2017) 187-202.

this fact, friability was primarily affected by the content of Avicel ${ }^{\circledR} \mathrm{PH} 200$, whereas Avicel ${ }^{\circledR}$ PH 101 had smaller effect on friability.

Tablet structure is shown in microscopic images (Fig. 3). Ground Cornelian cherry fruits differ from the MCC fillers by their dark colour. Apparently, visible dispergation of individual ground fruit particles is more regular in tablets with Avicel ${ }^{\mathbb{B}} \mathrm{PH} 101$ than in tablets containing Avicel ${ }^{\circledR} \mathrm{PH} 200$. This can also explain better mechanical properties of tablets containing Avicel ${ }^{\circledR} \mathrm{PH} 101$, since the MCC particles create more mutual contact surfaces and the tablet quality is better. Individual particles of ground Cornelian cherry fruits, which are plastic and difficult to compress, are separated according to the properties of Avicel ${ }^{\circledR} \mathrm{PH}$ 101. This can wedge between bigger particles, which was documented by physical evaluation of tableting blends (20).

\section{Stability evaluation}

Evaluation of stability testing was performed using interaction plots, where mean values of variables depending on two factors are plotted. This type of graph makes it possible to compare variable changes depending on the stress conditions for each MCC concentration separately. Statistically insignificant effect of compression pressure on tablet parameters was confirmed by ANOVA ( $p$-values $>0.05)$. Mean values for each combination of MCC concentration and MCC type are plotted in the graph, i.e., averaging of values relating to the three compression pressures.

It can be implied from stability evaluation (Table IV) that tablet quality changed considerably, predominantly worsened. ANOVA revealed a statistically significant effect of storage conditions on almost all the parameters measured: friability $(p=0.009)$, disintegration time $(p=0.004)$, density $(p=0.008)$, diameter $(p=0.003)$ and height $(p=0.005)$. The difference in tablet mass before and after stability testing was not significant, but the value $(p=0.094)$ was only slightly higher than the level of significance $(a=0.05)$.

Apparently, deteriorated quality occurred due to the hygroscopicity of dried plant material consisting of cellulose fibres (23). This fact is also confirmed by the tablet mass gain shown in Fig. 4a. Water absorption was uneven, resulting in unacceptable maximum deviations of mass uniformity.

An interesting relationship between the amount of MCC and tablet density is represented in Fig. 4b. Obviously, tablet density increased with the amount of MCC, being higher in tablets comprising Avice ${ }^{\circledR} \mathrm{PH}$ 101. The density lowered after stability testing in samples containing $50 \%$ MCC because of water absorption and tablet swelling. MCC compressed into tablets swells more extensively than other common excipients. Therefore, during stability studies, moisture affects the batches comprising a high content of MCC (24).

After stability storage, the tablet hardness/tensile strength was immeasurable in almost all samples. Hardness/tensile strength was successfully measured only in tablets consisting of $50 \%$ Avicel $^{\circledR} \mathrm{PH} 101$ and it was considerably lowered compared to the original values, regardless of compression pressure. Since tablet dimensions changed only minimally during stability testing, the values of hardness and tensile strength still correlate.

Samples produced using the lowest compression pressure exceeded the pharmacopoeial limit for friability. Other samples complied with the criterion, but friability values increased substantially relative to the original values (Fig. 4c). Evidently, the in- 


\begin{tabular}{|c|c|c|c|c|c|c|c|c|c|c|c|c|c|c|}
\hline \multirow{2}{*}{ Batch name } & \multicolumn{3}{|c|}{ 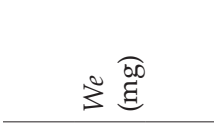 } & \multicolumn{2}{|c|}{$\ddot{\theta} \Xi$} & \multicolumn{2}{|c|}{ 孞 } & \multirow{2}{*}{$\frac{12}{\frac{2}{2}}$} & \multicolumn{2}{|c|}{$\stackrel{\Xi}{\underline{Z}}$} & \multicolumn{4}{|c|}{ 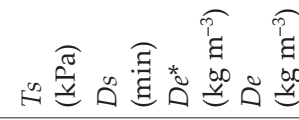 } \\
\hline & $\frac{\stackrel{\vartheta}{\Xi}}{\rho}$ & की & H & $\frac{\mathscr{\vartheta}}{ٍ}$ & ڤ & $\frac{\mathscr{D}}{ٍ}$ & ڤ & & $\frac{\stackrel{9}{J}}{\stackrel{\pi}{5}}$ & \begin{tabular}{l}
0 \\
\multirow{2}{*}{}
\end{tabular} & $\frac{\stackrel{0}{2}}{\pi}$ & $\frac{\stackrel{9}{3}}{\stackrel{\pi}{5}}$ & $\frac{\stackrel{0}{3}}{\frac{\pi}{5}}$ & $\frac{\stackrel{2}{3}}{\sqrt[\pi]{3}}$ \\
\hline \multicolumn{15}{|c|}{ After 6 months in $40{ }^{\circ} \mathrm{C} ; 75 \% \mathrm{RV}$} \\
\hline MCC 101_12.5\%_1 & 154.7 & 2.6 & 4.7 & 6.37 & 7.5 & 3.67 & 2.6 & 4.82 & \multicolumn{2}{|c|}{ NA } & NA & 8 & 1323 & 1096 \\
\hline MCC 101_12.5\%_2 & 147.1 & 1.8 & 3.3 & 6.71 & 2.0 & 3.57 & 2.5 & 1.06 & \multicolumn{2}{|c|}{ NA } & NA & 8 & 1166 & 1071 \\
\hline MCC 101_12.5\%_3 & 159.3 & 1.8 & 3.6 & 6.55 & 4.6 & 3.69 & 3.5 & 0.92 & \multicolumn{2}{|c|}{ NA } & NA & 9 & 1282 & 1122 \\
\hline MCC 101_25\%_1 & 159.4 & 1.6 & 3.5 & 7.07 & 2.2 & 3.61 & 2.4 & 0.79 & \multicolumn{2}{|c|}{ NA } & NA & 3 & 1125 & 1148 \\
\hline MCC 101_25\%_2 & 151.1 & 6.1 & 9.3 & 6.85 & 5.5 & 3.42 & 5.7 & 0.84 & \multicolumn{2}{|c|}{ NA } & NA & 3 & 1199 & 1149 \\
\hline MCC 101_25\%_3 & 157.8 & 2.7 & 4.3 & 6.73 & 5.5 & 3.60 & 2.7 & 0.67 & \multicolumn{2}{|c|}{ NA } & NA & 3 & 1233 & 1140 \\
\hline MCC 101_50\%_1 & 145.6 & 4.3 & 10.0 & 7.40 & 0.4 & 3.42 & 2.0 & 1.38 & 4.58 & 11.3 & 115.27 & 1 & 990 & 1107 \\
\hline MCC 101_50\%_2 & 153.5 & 2.1 & 4.2 & 7.40 & 0.9 & 3.50 & 1.7 & 0.68 & 4.93 & 23.4 & 121.24 & 2 & 1020 & 1140 \\
\hline MCC 101_50\%_3 & 151.0 & 2.6 & 3.8 & 7.36 & 0.6 & 3.46 & 2.2 & 0.74 & 6.62 & 9.0 & 165.58 & 2 & 1026 & 1135 \\
\hline MCC 200_12.5\%_1 & 153.7 & 1.5 & 2.4 & 6.68 & 1.1 & 3.60 & 3.0 & 0.61 & \multicolumn{2}{|c|}{ NA } & NA & 16 & 1219 & 1110 \\
\hline MCC 200_12.5\%_2 & 166.4 & 3.3 & 5.2 & 6.57 & 3.0 & 3.93 & 5.4 & 0.46 & \multicolumn{2}{|c|}{ NA } & NA & 12 & 1250 & 1101 \\
\hline MCC 200_12.5\%_3 & 163.4 & 3.8 & 6.4 & 6.79 & 1.0 & 3.86 & 2.1 & 0.48 & \multicolumn{2}{|c|}{ NA } & NA & 16 & 1170 & 1101 \\
\hline MCC 200_25\%_1 & 149.3 & 3.3 & 5.8 & 7.13 & 1.0 & 3.53 & 2.3 & 1.41 & \multicolumn{2}{|c|}{ NA } & NA & 9 & 1060 & 1100 \\
\hline MCC 200_25\%_2 & 164.4 & 4.8 & 10.6 & 6.99 & 1. 6 & 3.90 & 5.1 & 0.84 & \multicolumn{2}{|c|}{ NA } & NA & 7 & 1099 & 1096 \\
\hline MCC 200_25\%_3 & 154.7 & 2.6 & 4.7 & 6.78 & 8.9 & 3.66 & 3.1 & 1.10 & \multicolumn{2}{|c|}{ NA } & NA & 7 & 1171 & 1099 \\
\hline MCC 200_50\%_1 & 156.5 & 6.2 & 9.2 & 7.28 & 6.8 & 4.15 & 0.9 & NA & \multicolumn{2}{|c|}{ NA } & NA & 1 & 906 & 980 \\
\hline MCC 200_50\%_2 & 159.2 & 2.8 & 5.5 & 7.22 & 3.0 & 3.86 & 5.8 & 5.96 & \multicolumn{2}{|c|}{ NA } & NA & 1 & 1008 & 1072 \\
\hline MCC 200_50\%_3 & 151.2 & 2.1 & 3.4 & 7.29 & 1.1 & 3.59 & 2.4 & NA & \multicolumn{2}{|c|}{ NA } & NA & 2 & 1010 & 1095 \\
\hline
\end{tabular}

Batch names: MCC - microcrystalline cellulose, 101 and 200 are types of Avicel ${ }^{\circledR}, 12.5,25$ and $50 \%$ - MCC mass ratio, $1=20 \mathrm{MPa} ; 2=60 \mathrm{MPa} ; 3=100 \mathrm{MPa}$; We-mass, $T_{\max }$ - maximal deviated value (\%), Di-diameter, $\mathrm{He}$ - height, $\mathrm{Fr}$ - friability, $\mathrm{Ha}$ - hardness, Ts - tensile strength, $\mathrm{Ds}$ - disintegration, $\mathrm{De}$ - density ( ${ }^{*}$ for measured $\mathrm{D} i$ values), NA - not applicable.

crease in diameter and height in tablets containing $50 \% \mathrm{MCC}$ was caused by water absorption and tablet swelling as well. Changes in quality due to moisture are well documented in the literature (25).

Disintegration time was the only characteristic that improved after stability storage (Fig. 4d). Improvement was apparent mainly in samples with lower amounts of MCC. Due to water absorption, the effect of cohesive forces decreased and the tablets disintegrated rapidly (26).

The tablets comprising $50 \%$ Avicel $^{\circledR} \mathrm{PH} 101$ produced by compression pressure of $100 \mathrm{MPa}$ retained acceptable physical parameters during the 6 -month long storage at 

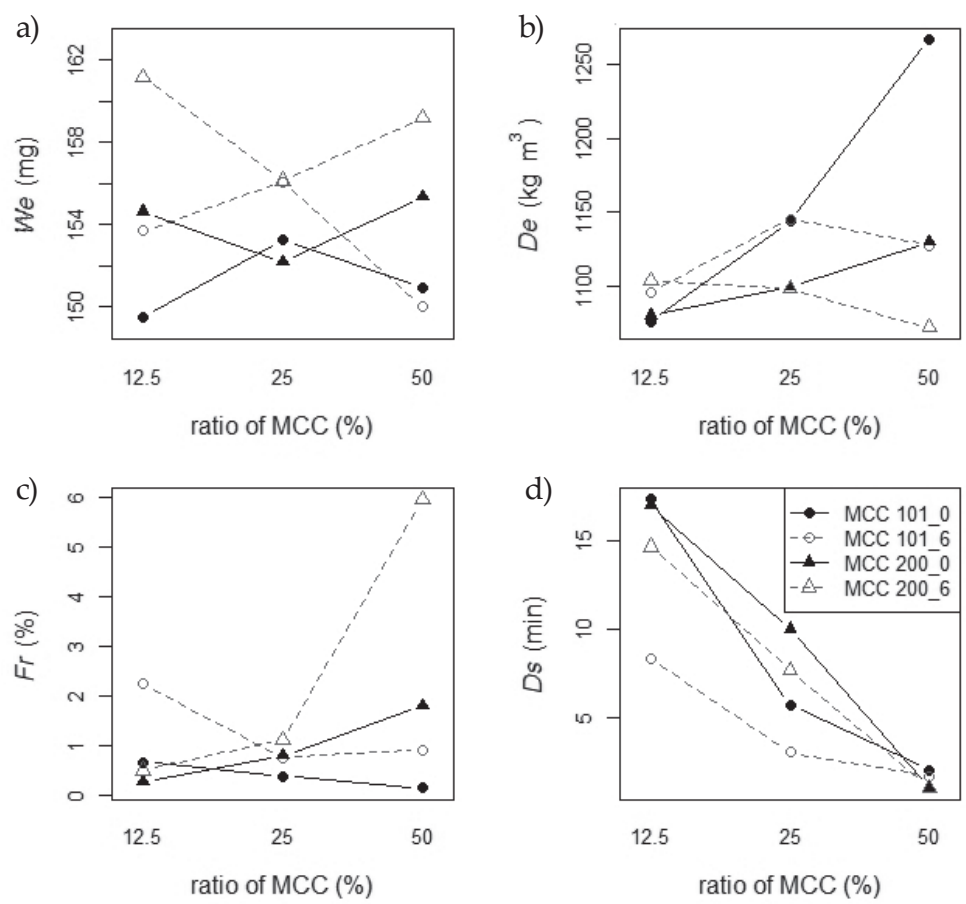

Fig. 4. Interaction plot for: a) mass, b) density, c) friability and d) disintegration time: samples with MCC 101 and MCC 200 (differentiated by symbols); original samples (black, solid line) vs. samples after stress conditions (grey, dashed line).

$40{ }^{\circ} \mathrm{C}$ and $75 \% \mathrm{RH}$. Although tablet hardness/tensile strength was relatively low, friability values passed the pharmacopoeial criterion, indicating sufficient mechanical resistance. Thus, these tablets can be considered as physically stable (27).

\section{Further process modifications}

It can be assumed that tableting blends containing $50 \%$ Avicel $^{\circledR} \mathrm{PH} 101$ resulted in high-quality tablets that satisfy the pharmacopoeial criteria. However, mass uniformity and hardness/tensile strength of tablets need to be improved. Changing the particle size of tableting mixtures can lead to amelioration of mass uniformity (28). Tablet hardness/tensile strength can be bettered by increasing the amount of compressed material using a compression matrix with increased diameter. This can also improve mass uniformity by increasing the particle size to tablet diameter ratio. For that reason, ground Cornelian cherry fruits were divided into two fractions with different particle sizes (up to $800 \mu \mathrm{m}$ and over $800 \mu \mathrm{m}$ ) and processed into tableting mixtures of identical composition. Tablets of $10 \mathrm{~mm}$ diameter and $400 \mathrm{mg}$ mass were compressed using compression pressures of 20 and $40 \mathrm{MPa}$. The results of the experiment were published individually and inform about the possibility of influencing quality parameters of the 


\begin{tabular}{|c|c|c|c|c|c|c|c|c|c|c|c|c|c|}
\hline \multirow[t]{2}{*}{ Batch name } & \multicolumn{3}{|c|}{ בे ह્छ } & \multicolumn{2}{|c|}{ 苂 } & \multicolumn{2}{|c|}{ ‡ี ह્छ } & \multirow{2}{*}{ 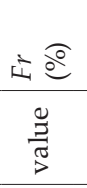 } & \multicolumn{2}{|c|}{$\stackrel{ \pm}{\underline{Z}}$} & \multicolumn{3}{|c|}{ 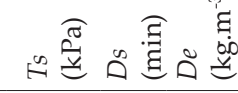 } \\
\hline & $\underset{\frac{\pi}{\pi}}{\stackrel{\Xi}{\supset}}$ & $\begin{array}{l}0 \\
2\end{array}$ & 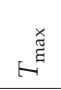 & 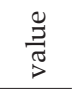 & ڤิ & $\stackrel{\frac{\pi}{7}}{\frac{\pi}{D}}$ & कि & & $\underset{\frac{\pi}{\pi}}{\stackrel{\pi}{D}}$ & $\begin{array}{l}\text { के } \\
\text { \& }\end{array}$ & $\stackrel{\frac{\pi}{J}}{\frac{\pi}{D}}$ & $\stackrel{\frac{\pi}{\pi}}{\frac{\pi}{D}}$ & $\frac{\stackrel{0}{7}}{\frac{\pi}{7}}$ \\
\hline MCC 101_50\%_<800_1 & 388.6 & 1.8 & 4.5 & 10.08 & 0.55 & 5.19 & 1.1 & 0.11 & 65.4 & & 796.25 & 2 & 938.7 \\
\hline MCC 101_50\%_<800_2 & 402.8 & 0.8 & 2.2 & 10.06 & 0.61 & 5.09 & 1.2 & 0.07 & 101.3 & 4.1 & 1260.07 & 3 & 996.1 \\
\hline MCC $101 \_50 \% \_>800 \_1$ & 392.6 & 2.6 & 5.5 & 10.15 & 1.01 & 5.59 & 1.5 & 0.50 & 42.9 & & 481.59 & 1 & 868.4 \\
\hline MCC $101 \_50 \% \_>800 \_2$ & 390.2 & 3.5 & 6.4 & 10.09 & 0.93 & 5.34 & 3.8 & 0.32 & 56.4 & & 666.73 & 1 & 914.3 \\
\hline
\end{tabular}

Batch names in code: MCC 101 - Avicel ${ }^{\circledR} \mathrm{PH} 101,<800$ - fraction under 0.800 mm sieve mesh, $>800$ - fraction above $0.800 \mathrm{~mm}$ sieve mesh, $1=20 \mathrm{MPa} ; 2=40 \mathrm{MPa}$; We - mass; $T_{\max }-$ maximal deviated value (\%), Di - diameter, $\mathrm{He}-$ height, $\mathrm{Fr}$ - friability, $\mathrm{Ha}$ - hardness, Ts - tensile strength, $\mathrm{Ds}$ - disintegration, De - density.

tablets and tableting blends by changing the quantity of Aerosil 200, and by selecting a specific particle size of plant material (8). This study analyses the relationship between the type and concentration of microcrystalline cellulose in relation to quality parameters of tablets and tableting blends. Partial results (Table V), which have not been published yet, are presented below.

Mass uniformity considerately improved with increased size of the compression matrix and decreased particle size of ground Cornelian cherry fruit. Acceptable hardness/tensile strength, friability and disintegration time were reached in tablets produced using both compression pressures. The tablets prepared from tableting blends comprising bigger particles passed the mass uniformity evaluation, but RSD and individual deviations doubled. The hardness/tensile strength was lowered and friability was increased, yet still acceptable. The disintegration time was shortened.

\section{CONCLUSIONS}

A method for the preparation of tablets containing ground Cornelian cherry fruit was developed. Cryogenic grinding in a high shear mixer with addition of $1 \%$ colloidal silica was proven effective for dry plant material processing. To prepare tablets of acceptable quality, microcrystalline cellulose in concentrations of at least $50 \%$, was needed as filler. Tablets containing Avicel ${ }^{\circledR}$ PH 101 achieved acceptable physical properties even after storage under accelerated stability conditions $\left(6\right.$ months, $40^{\circ} \mathrm{C}$ and $\left.75 \% \mathrm{RH}\right)$. Tablet mass uniformity can be further improved by using finely ground fruits and increased tablet mass and diameter.

Abbreviations: ANOVA - analysis of variance, $C I$ - Carr compressibility index, $D_{\mathrm{B}}$ - bulk density, $D_{\mathrm{T}}$ - tapped density, $H R$ - Hausner ratio, MCC - microcrystalline cellulose, PC - principal component, PCA - principal component analysis.

Acknowledgements. - The authors declare no conflict of interest. This research did not receive any specific grant from funding agencies in the public, commercial, or not-for-profit sectors. 
A. Franc et al.: E Influence of concentration and type of microcrystalline cellulose on the physical properties of tablets containing Cornelian cherry fruits, Acta Pharm. 67 (2017) 187-202.

\section{REFERENCES}

1. B. Hennig, A. S. Ettinger, R. J. Jandacek, S. Koo, C. McClain, H. Seifried, A. Silverstone, B. Watkins and W. A. Suk, Using nutrition for intervention and prevention against environmental chemical toxicity and associated diseases, Environ. Health Perspect. 115 (2007) 493-495; DOI: 10.1289/ehp.9549.

2. V. Katalinic, M. Milos, T. Kulisic and M. Jukic, Screening of 70 medicinal plant extracts for antioxidant capacity and total phenols, Food Chem. 94 (2006) 550-557; DOI: 10.1016/j.foodchem.2004.12.004.

3. İ. Gülçin, Ş. Beydemir, G. Şat and Ö. İ. Küfrevioğlu, Evaluation of antioxidant activity of cornelian cherry (Cornus mas L.), Acta Aliment. 34 (2005) 193-202; DOI: 10.1556/aalim.34.2005.2.13.

4. L. J. McGaw, A. K. Jage and J. Van Staden, Antibacterial, anthelmintic and anti-amoebic activity in South African medicinal plants, J. Ethnopharmacol. 72 (2000) 247-263; DOI: 10.1016/s03788741(00)00269-5.

5. B. Jayaprakasam, L. K. Olson, R. E. Schutzki, M. H. Tai and M. G. Nair, Amelioration of obesity and glucose intolerance in high-fat-fed C57BL/6 mice by anthocyanins and ursolic acid in Cornelian cherry (Cornus mas), J. Agric. Food Chem. 54 (2006) 243-248; DOI: 10.1021/jf0520342.

6. S. Asgary, R. Kelishadi, M. Rafieian-Kopaei, S. Najafi, M. Najafi and A. Sahebkar, Investigation of the lipid-modifying and antiinflammatory effects of Cornus mas L. supplementation on dyslipidemic children and adolescents, Pediatr. Cardiol. 34 (2013) 1729-1735; DOI: 10.1007/s00246-0130693-5.

7. G. E. Pantelidis, M. Vasilakakis, G. A. Manganaris and G. Diamantidis, Antioxidant capacity, phenol, anthocyanin and ascorbic acid contents in raspberries, blackberries, red currants, gooseberries and Cornelian cherries, Food Chem. 102 (2007) 777-783; DOI: 10.1016/j.foodchem.2006.06.021.

8. S. Kurhajec, A. Franc, P. Doležel and D. Sabadková, Quality by design approach: antioxidant activity of the tablets containing cornelian cherry fruits in relation to their composition and physical properties, Pharm. Dev. Technol. Epub (2016); 1-8; DOI: 0.3109/10837450.2015.1135345.

9. R. O. B. Wijesekera, The Medicinal Plant Industry, CRC Press, Boca Raton 1991.

10. T. Koyuncu, İ. Tosun and Y. Pinar, Drying characteristics and heat energy requirement of cornelian cherry fruits (Cornus mas L.), J. Food Eng. 78 (2007) 735-739; DOI: 10.1016/j.jfoodeng.2005.09.035.

11. L. Gallo, M. V. Ramírez-Rigo, J. Piña, S. Palma, D. Allemandi and V. Bucalá, Valeriana officinalis dry plant extract for direct compression: preparation and characterization, Sci. Pharm. 80 (2012) 1013; DOI: 10.3797/scipharm.1206-05.

12. European Pharmacopoeia, $8^{\text {th }}$ ed., Council of Europe, Strasbourg 2013; DOI: 0.1007/978-3-211-898369_515.

13. The United States Pharmacopeia 39, NF 34, U.S. Pharmacopeial Convention, Rockville, MD, 2016.

14. R Core Team, A Language and Environment for Statistical Computing (R Foundation for Statistical Computing. $R$ foundation for statistical computing 2012; https://www.r-project.org; access date June 30 2016.

15. S. Kalia, Cryogenic processing: a study of materials at low temperatures, J. Low Temp. Phys. 158 (2010) 934-945; DOI: 10.1007/s10909-009-0058-x.

16. E. Doelker, D. Massuelle, F. Veuillez and P. Humbert-Droz, Morphological, packing, flow and tableting properties of new Avicel types, Drug Dev. Ind. Pharm. 21 (1995) 643-661; DOI: 10.3109/03639049509048132.

17. M. K. Taylor, J. Ginsburg, A. J. Hickey and F. Gheyas, Composite method to quantify powder flow as a screening method in early tablet or capsule formulation development, AAPS PharmSciTech $\mathbf{1}$ (2000) 20-30; DOI: 10.1208/pt010318.

18. K. Seppälä, J. Heinämäki, J. Hatara, L. Seppälä and J. Yliruusi, Development of a new method to get reliable powder flow characteristics using only 1 to $2 \mathrm{~g}$ of powder, AAPS PharmSciTech 11 (2010) 402-408; DOI: 10.1208/s12249-010-9397-9. 
19. R. B. Shah, M. A. Tawakkul and M. A. Khan, Comparative evaluation of flow for pharmaceutical powders and granules, AAPS PharmSciTech 9 (2008) 250-258; DOI: 10.1208/s12249-008-9046-8.

20. E. Lahdenpää, M. Niskanen and J. Yliruusi, Study of some essential physical characteristics of three Avicel ${ }^{\circledR}$ PH grades using a mixture design, Eur. J. Pharm. Biopharm. 42 (1996) 177-182.

21. J. K. Prescott and R. Hoodfeld, Maintaining product uniformity and uninterrupted flow to directcompression tableting presses, Pharm. Technol. 18 (1994) 98-98.

22. C. Reimann, P. Filzmoser, R. Garret and R. Dutter, Statistical data analysis explained: applied environmental statistics with $R$, John Wiley \& Sons, Chichester 2008; DOI: 10.1002/9780470987605.

23. R. Elbaum, S. Gorb and P. Fratzl, Structures in the cell wall that enable hygroscopic movement of wheat awns, J. Struct. Biol. 164 (2008) 101-107; DOI: 10.1016/j.jsb.2008.06.008.

24. Y. E. Zhang and J. B. Schwartz, Effect of diluents on tablet integrity and controlled drug release, Drug Dev. Ind. Pharm. 26 (2000) 761-765; DOI: 10.1081/DDC-100101295.

25. S. Dawoodbhai and C. T. Rhodes, The effect of moisture on powder flow and on compaction and physical stability of tablets, Drug Dev. Ind. Pharm. 15 (1989) 1577-1600.

26. Y. Bi, H. Sunada, Y. Yonezawa, K. Danjo, A. Otsuka and K. Iida, Preparation and evaluation of a compressed tablet rapidly disintegrating in the oral cavity, Chem. Pharm. Bull. 44 (1996) 2121-2127.

27. WHO, Stability testing of active pharmaceutical ingredients and finished pharmaceutical products. WHO Technical Report Series. 2009; http://www.ich.org/fileadmin/Public_Web_Site/ICH_Products/ Guidelines/Quality/Q1F/Stability_Guideline_WHO.pdf; access date June 5, 2016.

28. J. Vercruysse, A. Burggraeve, M. Fonteyne, P. Cappuyns, U. Delaet, I. Van Assche, T. De Beerc, J. P. Remona and C. Vervaet, Impact of screw configuration on the particle size distribution of granules produced by twin screw granulation, Int. J. Pharm. 479 (2015) 171-180; DOI: 10.1016/j. ijpharm.2014.12.071. 